\section{OAK RIDGE \\ NATIONAL \\ LABORATORY}

MAARTIN MARTIETTAa

\section{TSC Plasma Halo Simulation of a DIII-D Vertical Displacement Episode}

RECEIVED

MAR 051993

OSTI 
This report has been reproduced directly from the best available copy.

Available to DOE and DOE contractors from the Office of Scientific and Technical Information, P.O. Box 62, Oak Ridge, TN 37831; prices available from (615) 576-8401, FTS 626-8401.

Available to the public from the National Technical Information Service, U.S. Department of Commerce, 5285 Port Royal Rd., Springfield, VA 22161.

This report was prepared as an account of work sponsored by an agency of the United States Government. Neither the United States Government nor any agency thereof, nor any of their employees, makes any warranty, express or implied, or assumes any legal liability or responsibility for the accuracy, completeness, or usefuiness of any information, apparatus, product, or process disclosed, or represents that its use would not infringe privately owned rights. Reference herein to any specific commercial product, process, or service by trade name, trademark, manufacturer, or otherwise, does not necessarily constitute or imply its endorsement, recommendation, or favoring by the United States Government or any agency thereof. The views and opinions of authors expressed herein do not necessarily state or reflect those of the United States Government or any agency thereof. 


\title{
TSC PLASMA HALO SIMULATION OF A DIII-D VERTICAL DISPLACEMENT EPISODE
}

\author{
R. O. Sayer \\ Y.K. M. Peng \\ S. C. Jardin \\ Princeton Plasma Physics Laboratory
A. G. Kellman
J. C. Wesley \\ General Atomics
}

Date Published: January 1993

Prepared for the Office of Fusion Energy

Budget Activity No. AT $101018 \mathrm{C}$

\author{
Prepared by \\ OAK RIDGE NATIONAL LABORATORY \\ Oak Ridge, Tennessee 37831-6285 \\ managed by \\ MARTIN MARIETTA ENERGY SYSTEMS, INC. \\ for the \\ U.S. DEPARTMENT OF ENERGY \\ under contract DE-AC05-84OR21400
}




\section{CONTENTS}

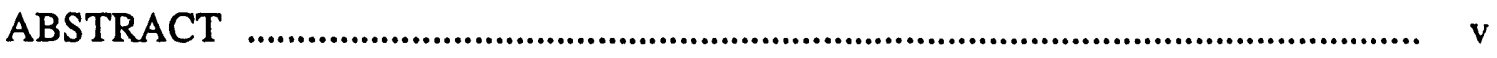

1. INTRODUCTION ................................................................................

2. TSC PLASMA HALO MODEL ............................................................... 3

3. EXPERIMENTAL AND SIMULATION RESULTS ………………................. 7

3.1 EXPERIMENTAL DATA ……......................................................... 7

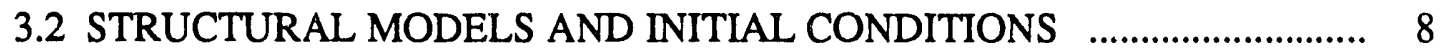

3.3 TIME EVOLUTION OF THE VDE ........................................................ 9

4. DISCUSSION AND CONCLUSIONS ……………...................................... 11

4.1 EFFECT OF INITIAL CONDITIONS ON VERTICAL, MOTION ................. 11

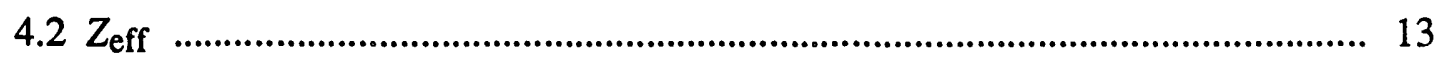

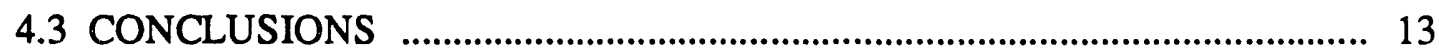

ACKNOWLEDGMENTS …..................................................................... 14

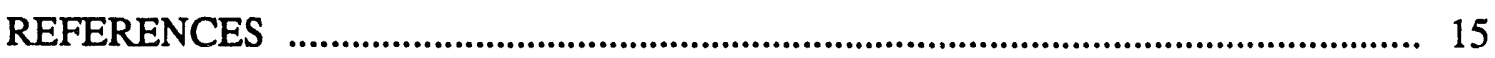




\begin{abstract}
A benchmark of the Tokamak Simulation Code (TSC) plasma halo model has been achieved by calibration against a DIII-D vertical displacement episode (VDE) consisting of vertical drift, thermal quench, and current quench. Inclusion of a 1- to 4-eV halo surrounding the main plasma was found to be necessary to match simulation and experimental results for plasma current decay, trajectory, toroidal and poloidal vessel currents, and magnetic probe and flux loop values for the entire VDE.
\end{abstract}




\section{INTRODUCTION}

Design of tokamak conducting structures is dominated by disruption-induced forces produced by plasma motion and current decay. Understanding of the mechanisms of disruptions and modeling with comprehensive, validated codes are essential for the realization of next-generation tokamak fusion devices. Attainment of adequate disruption characterization implies both augmentation of the meager experimental information on plasma properties during disruptions and benchmarks of simulation codes against experiment. We report here on a benchmark of the Tokamak Simulation $\operatorname{Code}^{1}$ (TSC) for an important class of disruptions that generate large localized forces on tokamak first-wall components.

One type of disruptive discharge that has been especially troublesome in machines with noncircular plasmas is a vertical displacement episode (VDE), in which there is a loss of vertical position control followed by vertical motion and shrinking of the plasma boundary. Typically the rapid loss of thermal energy begins when the safety factor near the edge, $q_{95}$, goes below 2 , and often the current decay does not occur until $q_{95}<1.5$ and the plasma is significantly off axis. The ensuing current decay often leads to large loads on first-wall segments close to the decaying plasma.

During VDEs there will be large electric fields, large heat flux across the plasma boundary, and gas entering the plasma from the wall. This causes a plasma halo to form in the scrape-off region just outside the main plasma. Although the temperature in this halo region is relatively low, it is sufficient to permit currents to flow both toroidally and poloidally. These currents may be produced by plasma motion, by diamagnetic flux changes due to rapid loss of thermal energy, and by decaying current in the main plasma. Damage to conducting structures in the Princeton Beta Experiment-Modification (PBX-M) during disruptive discharges ${ }^{2}$ is consistent with large poloidal currents entering the conductors from the plasma scrape-off layer (SOL). Recent observations 3,4 of 
DIII-D and Joint European Torus (JET) disruptions indicate that up to 20\% of the initial plasma current may flow between the SOL and the vacuum vessel. These poloidal SOL currents can lead to vertical vessel forces that are larger in magnitude than forces from the usual toroidal eddy currents.

Previous attempts have been made to model VDEs in tokamaks. Perhaps the most relevant to this work is that reported by Jensen and Skinner. ${ }^{5}$ They constructed a model that computes a sequence of plasma equilibria which approximate the time evolution of a DIII-D plasma during a VDE. By adding a tethering force to their plasma, they were able to force the plasma to follow approximately the trajectory of a DIII-D disruptive discharge. They then used the experimental values of the coil currents and adjusted the plasma resistivity to minimize the difference between the experimental data and corresponding simulated quantities. Their results for the plasma trajectory, plasma current, and vertical vessel forces were in approximate agreement with results deduced from static magnetohydrodynamic (MHD) fitting analyses. Although the model of Jensen and Skinner included a conducting halo, a single resistivity was used for both the halo and the main plasma regions. In addition, no comparison with experimental poloidal magnetic fields was made.

In this analysis we use TSC, which is a numerical model of a free-boundary axisymmetric plasma that interacts self-consistently with nearby conductors. Outside the main plasma region in TSC there is a low-density, low-temperature (a few electron volts) "halo" or SOL plasma in which force-free currents may flow along open field lines, intersect conductors, flow along minimum impedance paths, and return to the halo plasma. This TSC halo disruption model 6,7 has been used ${ }^{2}$ to reproduce both the dynamic plasma behavior and the passive stabilizing plate voltages measured during PBX-M disruptions by incorporation of a 3-eV halo. A disruptive discharge of a (circular) Tokamak Fusion Test Reactor (TFTR) plasma that moved radially inward after 
thermal quench has also been simulated ${ }^{7}$ with TSC with a halo. However, to date there has been no comparison of TSC halo predictions with experimental VDE discharges for highly elongated plasmas like those expected for the International Thermonuclear Experimental Reactor (ITER).

TSC has also been used to predict the evolution of plasma motion, current decay, induced eddy currents, and forces for the Burning Plasma Experiment (BPX) and ITER Conceptual Design Activity (CDA) designs. These calculations $6,8,9$ indicate very significant modifications in force distributions for vertical disruptions with a plasma halo. It is therefore important to calibrate the TSC halo model against experiment and to evaluate the sensitivity of predicted results to plasma model parameters, initial conditions, and structural design variants.

In this paper we describe the use of TSC to model all phases of a VDE in the DIII-D tokamak. We selected shot 63458 , a discharge for which data from a tile array in the vacuum vessel yielded direct measurement ${ }^{10}$ of poloidal current flowing between the plasma SOL and the vessel. In the following sections we describe the TSC plasma halo model, compare simulation and experimental results, and present some concluding remarks.

\section{TSC PLASMA HALO MODEL}

TSC solves axisymmetric resistive MHD equations in a domain that includes a plasma region, a plasma halo region, a vacuum region, and solid conductors. The computational grid is magnetically transparent, allowing control coils external to the grid to be incorporated. Circuit equations with realistic feedback systems are solved for conductors external and internal to the computational domain. Two-dimensional (2-D) velocity stream and potential functions, poloidal flux functions, and toroidal field functions 
describe the plasma, while surface-averaged MHD equations are used to evolve the plasma densities and temperatures.

An inertial enhancement technique is used to reduce the stiffness of the plasma force balance equation,

$$
\frac{\partial \mathbf{m}}{\partial t}+\mathbf{F}_{v}(m)=\mathbf{J} \times \mathbf{B}-\nabla p
$$

The inertial and viscosity terms on the left side of Eq. (1) are multiplied by enhancement factors chosen to make time integration feasible while keeping the left side small enough compared with the right side so that its effect on the plasma evolution is negligible.

Selected cases must be repeated with smaller enhancement factors to assure convergence in these quantities.

The equations solved by $\mathrm{TSC}^{1}$ have been changed in several ways to allow a description of the physics of a plasma with a surrounding halo. Let $\Psi_{L}$ be the limiting value of poloidal flux at the last closed plasma magnetic flux surface and $\Psi_{0}$ be the flux at the magnetic axis. We define the limiting value of the plasma halo region to be $\Psi_{H}=$ $\Psi_{L}+\alpha_{H}\left(\Psi_{L}-\Psi_{0}\right)$, where a value of $\alpha_{H}=0.4$ has been used in the calculations presented here. Thus, the region of the TSC computational grid that is not occupied by conductors is divided into three subregions:

$$
\begin{array}{ll}
\Psi_{0}<\Psi<\Psi_{L}, & \text { plasma region } \\
\Psi_{\mathrm{L}}<\Psi<\Psi_{\mathrm{H}}, & \text { halo region } \\
\Psi_{\mathrm{H}}<\Psi, & \text { vacuum region. }
\end{array}
$$

Regions of the domain that are topologically separated from the plasma region by an additional separatrix are also treated as part of the vacuum region, regardless of the value of poloidal flux. 
The same field and momentum evolution equations are solved in all three regions. However, the energy equations solved are quite different. In the plasma region, the temperature is evolved in time according to a transport model as described in Ref. 11. In the halo and vacuum regions, the temperatures are set to input variables $T_{\mathrm{H}}$ (halo) and $T_{\mathrm{V}}$ (vacuum). Normally, $T_{\mathrm{V}} \ll T_{\mathrm{H}}$ so that the halo region is a much better conductor than is the vacuum region.

The halo region represents the SOL plasma. Toroidal current will normally be induced in the halo region during a VDE in the same direction as the initial plasma toroidal current. The halo current will develop a poloidal component to remain force free. These force-free currents may flow along open field lines, intersect conductors, flow along minimum impedance paths, and return to the halo plasma. The TSC halo zodel also takes into account purely inductive poloidal and toroidal current transfer due to toroidal and poloidal flux changes, respectively. TSC main plasma and plasma halo regions are depicted schematically in Fig. 1.

In the halo region, to a good approximation the halo plasma stays in zero pressure force balance so that Eq. (1) effectively reduces to

$$
\mathbf{J} \times \mathbf{B}=\mathbf{0} .
$$

The implementation of the halo physics capability in the TSC code also necessitated modification of the boundary conditions used in the time integration of the 2-D variables describing the toroidal field and the plasma velocity. The magnetic field is represented in TSC in the usual way for an axisymmetric system,

$$
\mathbf{B}=\nabla \phi \times \nabla \Psi(R, Z)+g(R, Z) \nabla \phi,
$$


where $(R, \phi, Z)$ form a cylindrical coordinate system, $\Psi(R, Z)$ is the negative of the poloidal flux per radian, and $g(R, Z)=R B_{\mathrm{T}}$. It follows from Eq. (3) that the current density is given by

$$
\mu_{0} \mathbf{J}=\Delta^{*} \Psi \nabla \phi+\nabla g \times \nabla \phi
$$

where the first term on the right side of Eq. (4) represents the toroidal current density and the second term the poloidal current density. It is seen that the poloidal current is determined completely from the toroidal field function $g$.

The equation to advance $g$ in time comes from Faraday's law,

$$
\frac{\partial g}{\partial t}+R^{2} \nabla \cdot[-\nabla \phi \times \mathrm{E}]=0,
$$

where $\mathbf{E}$ is the electric field. If $g_{i j}$ is the finite difference approximation to the value of $g$ at the center of the computational zone $(i, j)$ with area $\Delta A$, then the discrete version of Eq. (5) is

$$
\frac{\Delta A}{R} \frac{\partial}{\partial t} g_{i j}=-\oint \mathbf{E} \cdot \mathbf{d l}=\sum_{k=1}^{4} \mathbf{E}_{k} \cdot \Delta \mathbf{l}
$$

where the contour integral on the right is around the four line segments that define the boundary of the zone. This is illustrated in Fig. 2 .

Equation (6) is solved everywhere on the computational grid. The evsluation of the right side consists of splitting the line integral into four line integrals around the four line segments surrounding the zone $(i, j)$. Each zone corner is one of four types-plasma, halo, vacuum, or conductor-and has the corresponding value of resistivity associated with it. The resistivity of each segment is defined as the average of the resistivity at each of the two endpoints. With the resistivity of the line segments so defined, one of two expressions is used for the electric field on the line segments defined in Eq. (6). If at least one endpoint is in the plasma, halo, or vacuum, the electric field is given by 


$$
\mathbf{E}=g \nabla \phi \times \mathbf{v}+(\nabla \phi \cdot \mathbf{v}) \nabla \Psi+\frac{\eta_{l l}}{\mu_{0}} \nabla g \times \nabla \phi
$$

where $\mathbf{v}$ is the fluid (plasma) velocity and a single value of $Z_{\text {eff }}$ is used for plasma, halo, and vacuum. If both endpoints are of the conductor type, then the electric field is given by

$$
\mathbf{E}=\frac{\eta_{c}}{\mu_{0}} \nabla g \times \nabla \phi
$$

where $\eta_{c}$ is the conductor resistivity.

The other boundary condition that had to be modified in TSC has to do with the plasma momentum $c$ nsity, or velocity. This modification allows the plasma, halo, or vacuum region to exisi in a zone adjacent to a conductor. This necessitates imposing the additional boundary condition that the normal component of the momentum density or velocity be zero on a zone segment when both endpoints are of the conductor type.

In the TSC formulation, the momentum density $\mathbf{m}=M_{i} n \mathbf{v}$ is represented in terms of a stream function, a toroidal component, and a potential:

$$
\mathbf{m}=\nabla \phi \times \nabla A+\nabla \Omega+\omega \nabla \phi .
$$

Thus on a zone segment with both endpoints of the conductor type, we impose the boundary condition

$$
\begin{array}{ll}
A=0 & \text { on segment endpoints, and } \\
\frac{\partial \Omega}{\partial n}=0 & \text { on the segment. }
\end{array}
$$

\section{EXPERIMENTAL AND SIMULATION RESULTS}

\subsection{EXPERIMENTAL DATA}

Data files for shot 63458 were extracted from the DIII-D data base. The data included output in 1-ms time intervals from 31 poloidal magnetic probes, 41 poloidal 
flux loops, 18 shaping (F) coils, 2 Ohmic (E) coils, power supply voltages, and various signals used for feedback on F coils. Special TSC routines were developed to read, interpolate, and use the data for feedback systems, and to facilitate comparison of experimental and simulation results. Figure 3 is a cross section of the DIII-D device showing the locations of the $\mathrm{F}$ coils, $\mathrm{E}$ coils, magnetic probes, flux loops, and vacuum vessel.

For this discharge, a tile current array in the divertor area yielded measurements of current flowing poloidally between the vacuum vessel and the plasma SOL. In Fig. 4 are shown plasma current, $Z_{\mathrm{mag}}$, and examples of tile currents vs time. This shot is characteristic of « VDE in that extensive vertical motion and significant flow of current between vessel and SOL occur before thermal quench.

\subsection{STRUCTURAL MODELS AND INITIAL CONDITIONS}

Detailed filamentary models were used to represent the vessel (218 filaments) and the $F$ and $E$ coils (457 filaments). Test runs in which a constant toroidal voltage was imposed on the computational grid and the toroidal field was rapidly ramped yielded vessel $L / R$ times of 6.9 (3.3) ms for toroidal (poloidal) current flow. A test of the TSC vessel model was performed by ramping one of the $E$ coils to a specified current with no plasma present. The observed and simulation toroidal vessel currents, compared in Fig. 5, are in excellent agreement. $L / R$ times for the $\mathrm{F}$ and $\mathrm{E}$ coils were about an order of magnitude longer than the $31-\mathrm{ms}$ simulation time.

For the initial TSC equilibrium ( $t=2664 \mathrm{~ms}$ ) the poloidal flux, magnetic field, and $\mathrm{F}$ coil currents were all in good agreement with experiment. The rms deviations in flux and field were $0.003 \mathrm{~Wb}$ and $0.005 \mathrm{~T}$, respectively. 


\subsection{TIME EVOLUTION OF THE VDE}

The simulation was run from 2664 to $2695 \mathrm{~ms}$ in order to encompass the entire VDE (vertical drift, thermal quench, and current quench). The plasma halo was characterized by fixed flux width $\alpha_{\mathrm{H}}=0.40, Z_{\mathrm{eff}}=2.0$, and temperature $T_{\mathrm{H}}$ that was constant within the halo region but variable in time. From an initial value of $1 \mathrm{eV}, T_{\mathrm{H}}$ was increased to $2 \mathrm{eV}$ at $2668.5 \mathrm{~ms}$, to $3 \mathrm{eV}$ at $2673 \mathrm{~ms}$, and to $4 \mathrm{eV}$ at $2679 \mathrm{~ms}$ to obtain best agreement with the magnetics data. A simplified F coil voltage feedback sche was used to maintain close coimspondence between simulated and experimental F coil currents.

The TSC poloidal flux at a time $(2680 \mathrm{~ms})$ just before thermal quench is shown in Fig. 6. Filamentiry representations of the vessel and coils are also depicted. At this time about $40 \mathrm{~A}$ A of poloidal current flows between the halo and the vessel bottom. Also shown is the reconstructed equilibrium for $t=2680 \mathrm{~ms}$ from the EFIT code. ${ }^{12}$ EFIT fits the probe, flux loop, and F coil data using a variable SOL width and 24 vessel segments. Excellent agreement is obtained for the magnetic axis and main plasma region; the TSC halo extent is about $25 \%$ greater than the EFIT halo extent at this time.

In Fig. 7 we illustrate the development of poloidal current flow with contour plots of the toroidal field function $g$ at thermal quench time $(2680 \mathrm{~ms})$ and at two times during the plasma current decay phase. The $g$ contours are streamlines whose spacing is an indication of the relative intensity of poloidal current flow. Midway through the plasma current decay there is as much poloidal current flowing between the vessel and the halo region as is flowing in the plasma region.

Figure 8 depicts the evolution of plasma current, toroidal vessel current, and poloidal halo vessel current. The TSC plasma current is in excellent agreement with the measured plasma current. TSC peak vessel toroidal currents $(300 \mathrm{kA})$ and poloidal currents $(170 \mathrm{kA})$ are in good agreement with the experimental values of $300 \mathrm{kA}$ and $200 \mathrm{kA}$, respectively. The thermal quench was triggered at $2680 \mathrm{~ms}$ by enhancement of 
the radial thermal conductivity by a large factor leading to increased resistivity in the main plasma and to the ensuing current quench. Also indicated in Fig. 8 are $T_{\mathrm{H}}$ values and the corresponding time ranges.

Figure 9 presents a global view of the time evolution of the magnetic probe data and calculated fields displayed on a cross section of the vessel. Each TSC curve and probe data set are plotted at the approximate $(R, Z)$ location of that probe. It can be seen that the fields near the vessel bottom increase as the plasma moves down and decrease rapidly during the current quench. In general, both the magnetics and flux evolution are tracked rather well by the simulation. The extreme rms deviations in flux and field are $0.008 \mathrm{~Wb}$ and $0.021 \mathrm{~T}$, respectively.

It can be seen in Fig. 8 that for $T_{\mathrm{H}}=4 \mathrm{eV}$ the simulation plasma current, $I_{\mathrm{p}}$, decays in accord with experiment. Both the vertical speed and the current decay rate, $d I_{\mathrm{p}} / d t$, are quite sensitive to $T_{\mathrm{H}} ; d I_{\mathrm{p}} / d t$ is also affected by the value chosen for the radial thermal conductivity enhancement factor, $F_{\mathrm{rtc}}$. To test the sensitivity of our results to $T_{\mathrm{H}}$, we simulated the first half of the current decay phase with $T_{\mathrm{H}}=6 \mathrm{eV}$ and adjusted $F_{\mathrm{rtc}}$ to give approximately the observed $d I_{\mathrm{p}} / d t$. We found that the extreme rms deviation in field was twice as large as the value for the 4-eV case. Similarly, a 2-eV halo gives significantly worse agreement with the magnetics data than does a $4-\mathrm{eV}$ halo. This behavior may be understood in terms of different effective current decay rates in the halo and main plasma regions. Larger $F_{\mathrm{rtc}}$ and higher $T_{\mathrm{H}}$ tend to give faster decay in the main plasma and slower decay in the halo, thus leading to a different pattern of magnetic field variation at probe locations near the halo.

Reconstructed equilibria for several times during this shot were generated with EFIT. Figure 10 illustrates the good correspondence between TSC (curves) and EFIT (circles) plasma parameters. As shown in Fig. 11, there is also good agreement between the net vertical vessel forces as determined from the dynamic TSC simulation and the 
forces calculated with EFIT. At the time of extreme force, the contribution from poloidal current is clearly dominant.

\section{DISCUSSION AND CONCLUSIONS}

\subsection{EFFECT OF INITIAL CONDITIONS ON VERTICAL MOTION}

The TSC simulation begins in a state slightly perturbed from an unstable equilibrium, and therefore small differences in the initial vertical displacement, $Z_{i}$, will produce different vertical trajectories. We consider these differences to be a reflection of the physical situation, namely that the plasma is undergoing a period of exponential growth in which small random fluctuations will be greatly amplified. We do not use a "tethering force" or other artificial force to prescribe a particular trajectory. We do increase $T_{\mathrm{H}}$ at three times during the 31-ms simulation to improve the agreement with magnetics data. Higher $T_{\mathrm{H}}$ has the effect of retarding vertical motion.

In preparing the simulation presented here, we have spent a considerable amount of time investigating the initial conditions that will reproduce the observed evolution of magnetic fields and fluxes for shot 63458 . We have found one such set of initial conditions, corresponding to $Z_{\mathrm{i}}=-0.1 \mathrm{~cm}$ and $T_{\mathrm{H}}=1 \mathrm{eV}$, that gives very good agreement with experiment. It is a validation of the TSC model that one can find any set of initial conditions that leads to a dynamic simulation that agrees with so many features of the data for the entire VDE time interval.

However, it follows that a different set of initial conditions would give rise to considerably different time trajectories than those observed for this particular disrupting discharge and also to different force patterns on the vacuum vessel. This underscores the point that, in trying to identify "most severe" disruption scenarios to bracket the design 
of a new device, a wide range of initial conditions must be explored, since the actual initial conditions for a given event will be impossible to predict a priori.

As an example of the effect of vaying $Z_{\mathrm{i}}$, we show in Fig. 12 results from three halo simulations, all with $T_{\mathrm{H}}=1 \mathrm{eV}$, for $t=2664-2670 \mathrm{~ms}$. During this time interval in shot 63458 , the plasma drifted from near midplane to about $8 \mathrm{~cm}$ below midplane. We plot $\Delta B_{\mathrm{rms}}$, the rms difference between TSC and experimental fields (summed over $31 \mathrm{mag}$ netic probe locations), vs $Z_{\mathrm{mag}}$ for each case: $Z_{\mathrm{i}}=-0.5 \mathrm{~cm},-0.1 \mathrm{~cm}$, and $0.4 \mathrm{~cm}$. The case with $Z_{1}=-0.1 \mathrm{~cm}$ gives by far the best fit to both the magnetics data and to the evolution of $Z_{\mathrm{mag}}$. Therefore, we adopted this initial equilibrium with $Z_{\mathrm{i}}=-0.1 \mathrm{~cm}$ and $T_{\mathrm{H}}=1 \mathrm{eV}$ as the starting point for our complete VDE simulation. It should be noted that many cases were run without a plasma halo. All such "no-halo" cases gave significantly worse agreement with experiment than did the halo case adopted here. For example, for a no-halo case $Z_{\mathrm{i}}=-0.1 \mathrm{~cm}, \Delta B_{\mathrm{rms}}$ at $t=2670 \mathrm{~ms}$ is 20 times larger than the value for the adopted halo simulation.

In Fig. 13 we compare vertical trajectories from four simulations with experimental $Z_{\text {mag }}$ values deduced from the magnetic probe data for the first $6 \mathrm{~ms}$ of vertical drift. Case (a), the adopted $Z_{\mathrm{i}}=-0.1 \mathrm{~cm}, T_{\mathrm{H}}=1 \mathrm{eV}$ simulation, agrees with experiment to better than $1 \mathrm{~cm}$ over this time range. Both the no-halo case (d) and the $Z_{\mathrm{i}}=-0.5 \mathrm{~cm}$, $T_{\mathrm{H}}=1 \mathrm{eV}$ case (c) diverge rapidly from experiment after the first 2 or $3 \mathrm{~cm}$ of vertical drift. For case (b), $Z_{\mathrm{i}}$ was $-0.5 \mathrm{~cm}$, and $T_{\mathrm{H}}$ was decreased from an initial value of $4 \mathrm{eV}$ to $1 \mathrm{eV}$ at $t=2667 \mathrm{~ms}$ and fixed at $1 \mathrm{eV}$ for $t>2667 \mathrm{~ms}$. This case also agrees well with experiment and shows that small differences in $Z_{\mathrm{i}}$ can be offset by different $T_{\mathrm{H}}$ values during the early part of the vertical drift when the plasma is still near midplane. However, after the plasma is more than about $2 \mathrm{~cm}$ below midplane ( $t>2667 \mathrm{~ms}$ ), $T_{\mathrm{H}}$ must be approximately $1 \mathrm{eV}$ to reproduce the observed trajectory. 


\section{$4.2 Z_{\text {eff }}$}

Estimates of $Z_{\text {eff }}$ in VDE-like situations are highly uncertain because of the poorly known admixture of high- $Z$ limiter and impurity material in the SOL. For the current decay phase of shot 63458 we find $T_{\mathrm{H}}=4 \mathrm{eV}$ for $Z_{\mathrm{eff}}=2.0$. Since $\eta_{\mathrm{H}} \sim \mathrm{Z}_{\mathrm{eff}} T_{\mathrm{H}}^{-3 / 2}$, our simulation result implies $2.5 \mathrm{eV}<T_{\mathrm{H}}<8.3 \mathrm{eV}$ if $1<Z_{\mathrm{eff}}<6$ and $T_{\mathrm{H}}$ is constant within the SOL. If, however, $T_{\mathrm{H}}$ increases linearly across the SOL, then $T_{\mathrm{H}}$ could be as high as $16 \mathrm{eV}$ at the inner halo edge for shot 63458 . This value is consistent with SOL temperatures of 15-25 eV measured for more recent VDE discharges in DIII-D using a newly installed multipulse Thomson scattering system.

\subsection{CONCLUSIONS}

A simulation with a simplified F coil feedback scheme and with a 1- to 4-eV plasma halo reproduces the plasma current decay evolution and gives reasonable agreement with flux loop and magnetic probe data. The extreme rms deviations in flux and field are $0.008 \mathrm{~Wb}$ and $0.021 \mathrm{~T}$, respectively. During the vertical drift phase the peak vertical speed is $110 \mathrm{~m} / \mathrm{s}$, corresponding to a growth time of about $2.5 \mathrm{~ms}$. During the current decay phase the peak vertical speed is $220 \mathrm{~m} / \mathrm{s}$. Peak predicted and measured vessel poloidal halo currents are $170 \mathrm{kA}$ and $200 \mathrm{kA}$, respectively. The predicted evolutions of plasma parameters and vertical vessel forces are in good agreement with values derived from EFIT reconstructed equilibria.

Simulations with no plasma halo yield much faster vertical motion and significantly worse agreement with magnetics and flux loop data than do halo simulations. Inclusion of a halo with a temperature of a few electron volts in the TSC calculations is necessary to obtain agreement with measured field and flux values for DIII-D shot 63458. 


\section{ACKNOWLEDGMENTS}

The authors are pleased to acknowledge valuable discussions with T. H. Jensen,

L. Lao, M. Schaffer, and D. J. Strickler. We are also indebted to L. Lao for providing the EFIT calculations for discharge 63458. 


\section{REFERENCES}

1. S. C. Jardin, N. Pomphrey, and J. DeLucia, "Dynamic Modeling of Transport and Positional Control of Tokamaks," J. Comput. Phys. 66, 481 (1986).

2. H. W. Kugel et al., "Induced Voltage and Eddy Current in the PBX-M Stabilizing Shell," Proceedings of the 16th European Conference on Controlled Fusion and Plasma Physics, Venice, Italy, March 13-17, 1989, European Physical Society, 1989.

3. A. G. Kellman et al., "Vertical Stability, High-Elongation, and the Consequences of Loss of Vertical Control on DIII-D," in Fusion Technology 1990: Proceedings of the 16th Symposium, North-Holland, Amsterdam, 1991.

4. M. A. Pick et al., "Evidence of Halo Currents in JET," in Proceedings of the 14th IEEE Symposium on Fusion Engineering, San Diego, 1991, IEEE, New York, 1992.

5. T. H. Jensen and D. G. Skinner, "Support of the Model for 'Vertical Displacement Episodes' from Numerical Simulation of Episodes Observed in the DIII-D Tokamak," Phys. Fluids B 2, 2358 (1990).

6. R. O. Sayer, Y-K. M. Peng, and S. C. Jardin, "TSC Halo Disruption-Induced Forces on the CIT Vacuum Vessel," Bull. Am. Phys. Soc. 35, 1921 (1990).

7. B. J. Merrill, S. C. Jardin, M. Ulrickson, and M. Bell, "Dynamics and Energy Flow in a Disrupting Tokamak Plasma," Fusion Eng. Des. 15, 163 (1991).

8. S. C. Jardin et al., "Magnetohydrodynamic Equilibrium and Stability," Fusion Technol. 21, 1123 (1992).

9. R. O. Sayer, ITER-IL-PH-8-0-17.

10. E. J. Strait, L. L. Lao, J. L. Luxon, and E. E. Reis, “Observation of Poloidal Current Flow to the Vacuum Vessel Wall during Vertical Instabilities in the DIII-D Tokamak," Nucl. Fusion 31, 527 (1991). 
11. S. C. Jardin, M. G. Bell, and N. Pomphrey, TSC Simulation of Ohmic Discharges in TFTR, PPPL-2839, Princeton Plasma Physics Laboratory, Princeton, N.J., April 1992.

12. L. L. Lao and T. H. Jensen, "Magnetohydrodynamic Equilibria of Attached Plasmas after Loss of Vertical Stability in Elongated Tokamaks," Nucl. Fusion 31, 1909 (1991). 
ORNL-DWG 91-2349 FED

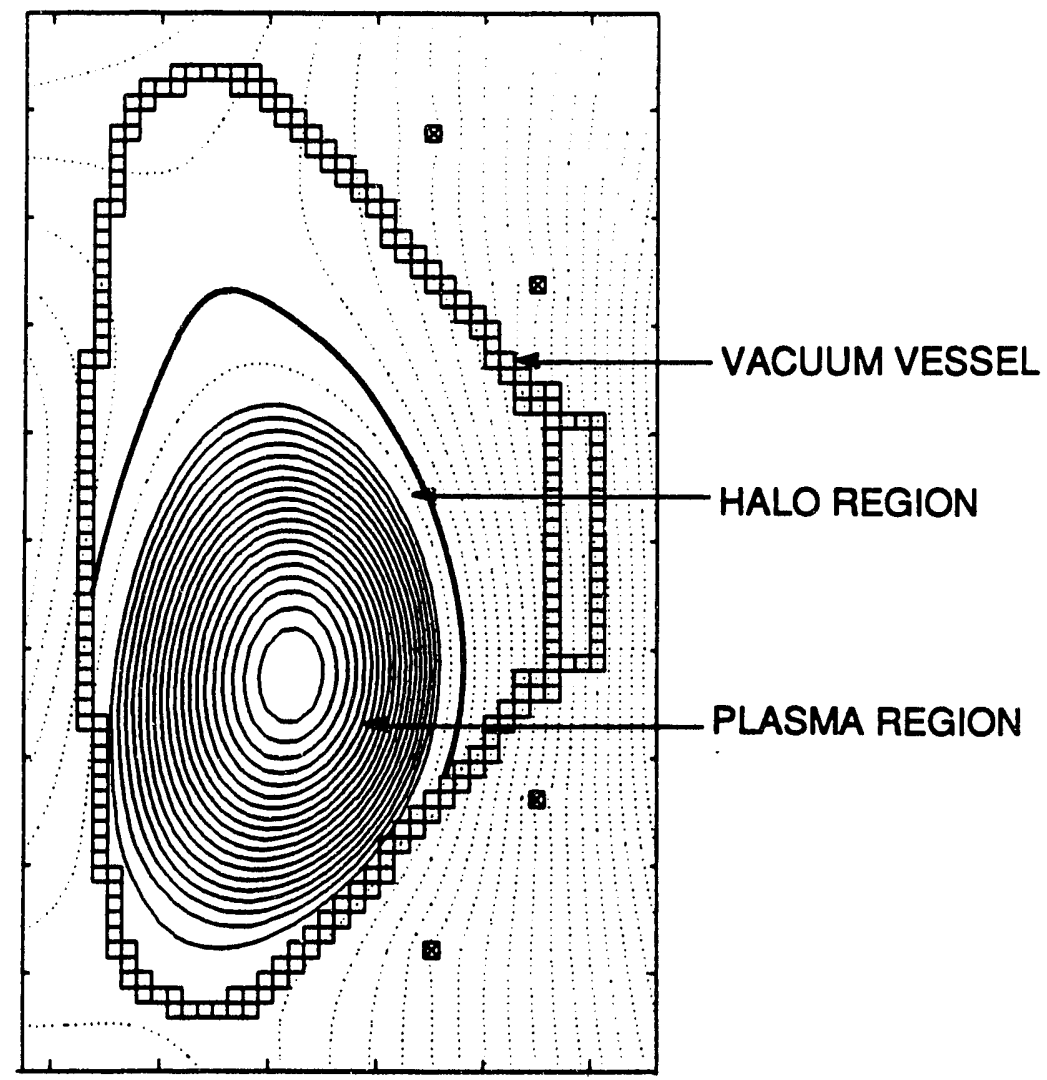

Fig. 1. Schematic representation of TSC plasma and halo regions. The halo region is bounded by the poloidally continuous vacuum vessel and by a specified increment in poloidal flux. 
OANL-DWG 92-3959 FED

\section{$A_{i j}, \eta_{i j}$}

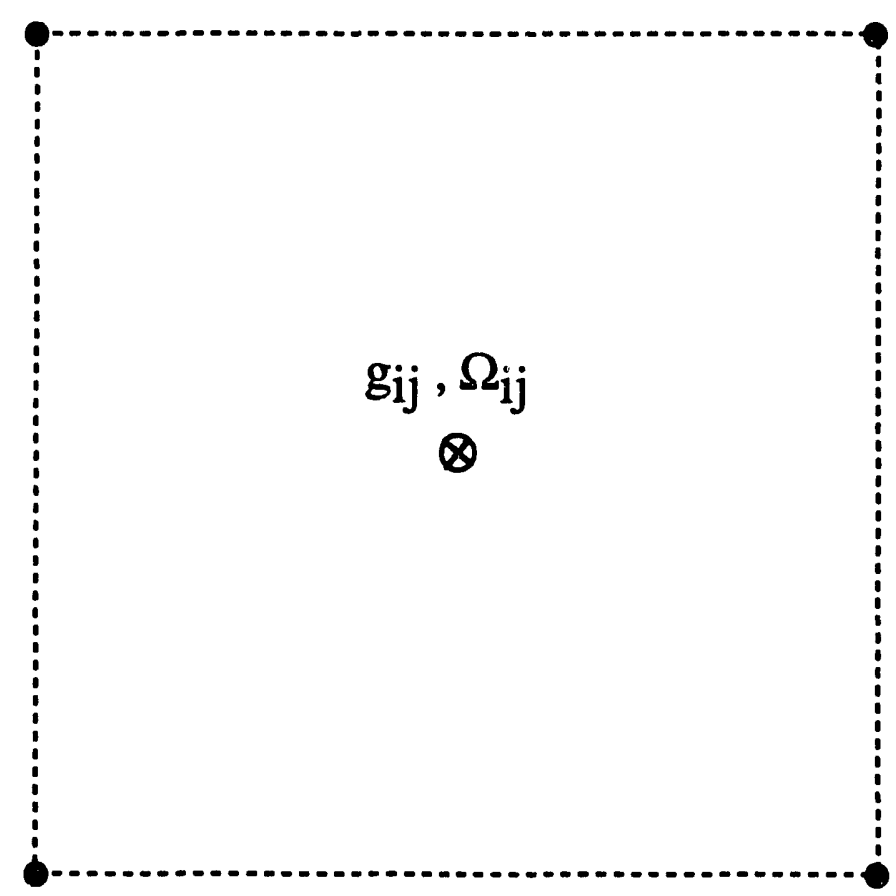

Fig. 2. The TSC computational grid has the toroidal field function $g_{i j}$ and the velocity potential $\Omega_{i j}$ defined in cell interiors. The velocity stream function $A_{i j}$ and resistivity $\eta_{i j}$ are defined on cell vertices. The resistivity at a line segment center is the average of the values at the endpoints. 
ORNL-DWG 92-3960 FED

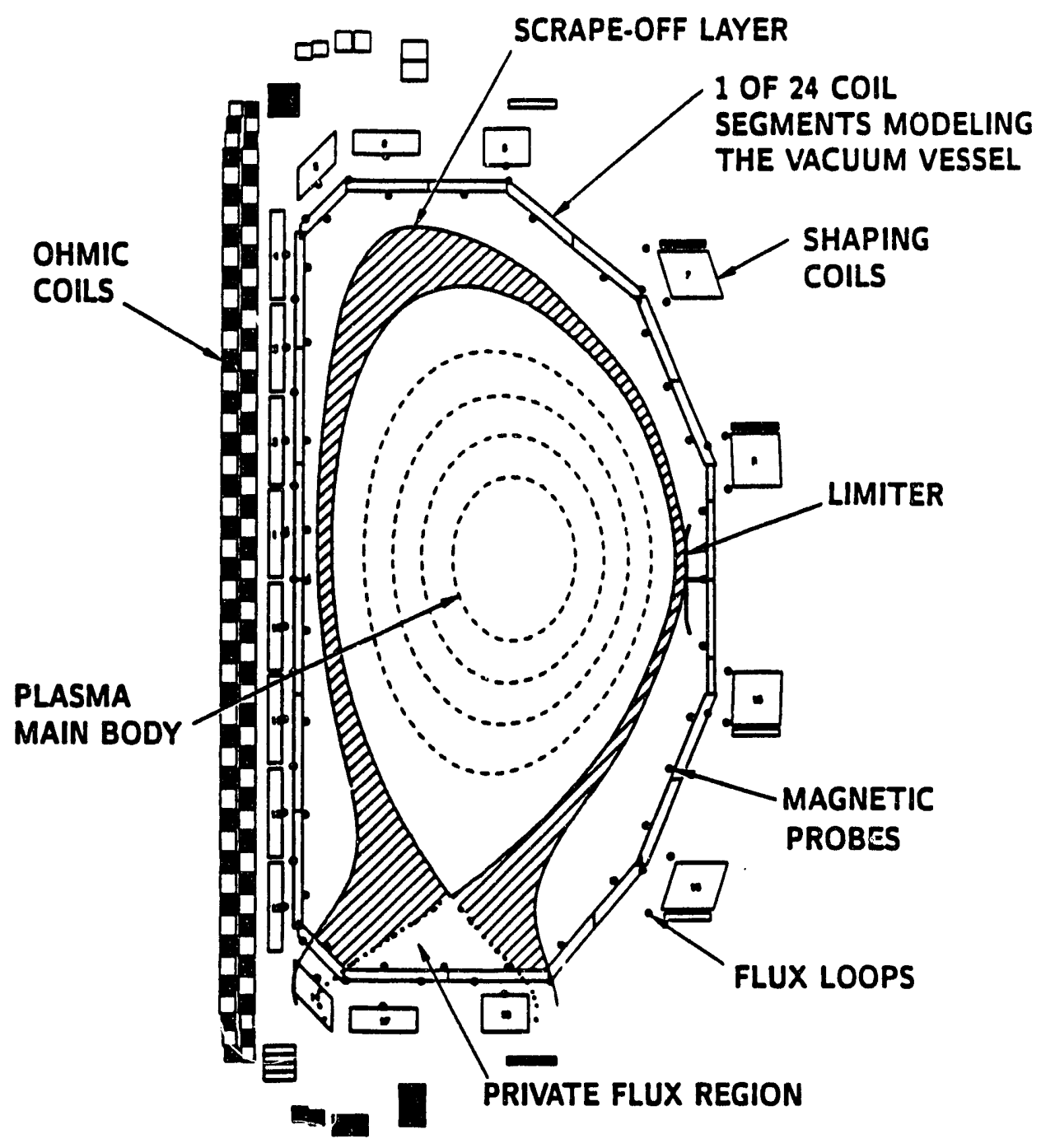

Fig. 3. Cross section of the DIII-D device, showing the locations of the Ohmic heating coils, the shaping $(\mathrm{F})$ coils, the vacuum vessel, the flux loops, and the magnetic probes. Source: L. L. Lao and T. H. Jensen, "Magnetohydrodynamic Equilibria of Attached Plasmas after Loss of Vertical Stability in Elongated Tokamaks," Nucl. Fusion 31, 1909 (1991). 
ORNL-DWG 92-3961R FED
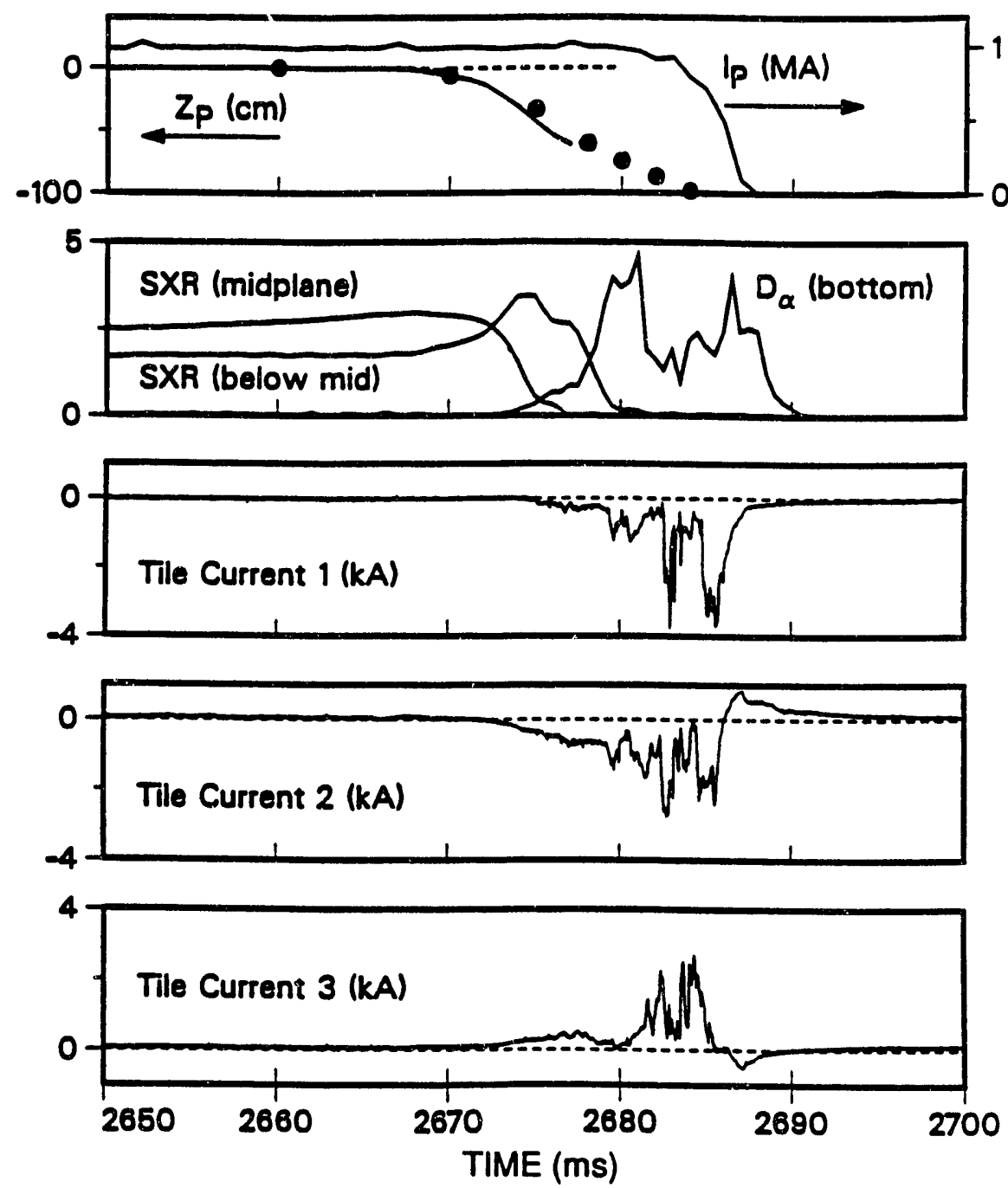

Fig. 4. Time traces of plasma parameters and diagnostic signals for DIII-D shot 63458. Shown are plasma current $I_{\mathrm{p}}$, vertical position of the magnetic axis from EFIT $Z_{\mathrm{p}}$ (solid circles), soft $X$-ray chords viewing the initial location of the magnetic axis and about $30 \mathrm{~cm}$ below, signals from a $\mathrm{D}_{\alpha}$ photodiode viewing the bottom of the vacuum vessel, and the three armor tile Rogowski loop signals. Source: E. J. Strait et al., "Observation of Poloidal Current Flow to the Vacuum Vessel Wall During Vertical Instabilities in the DIII-D Tokamak," Nucl. Fusion 31, 527 (1991). 


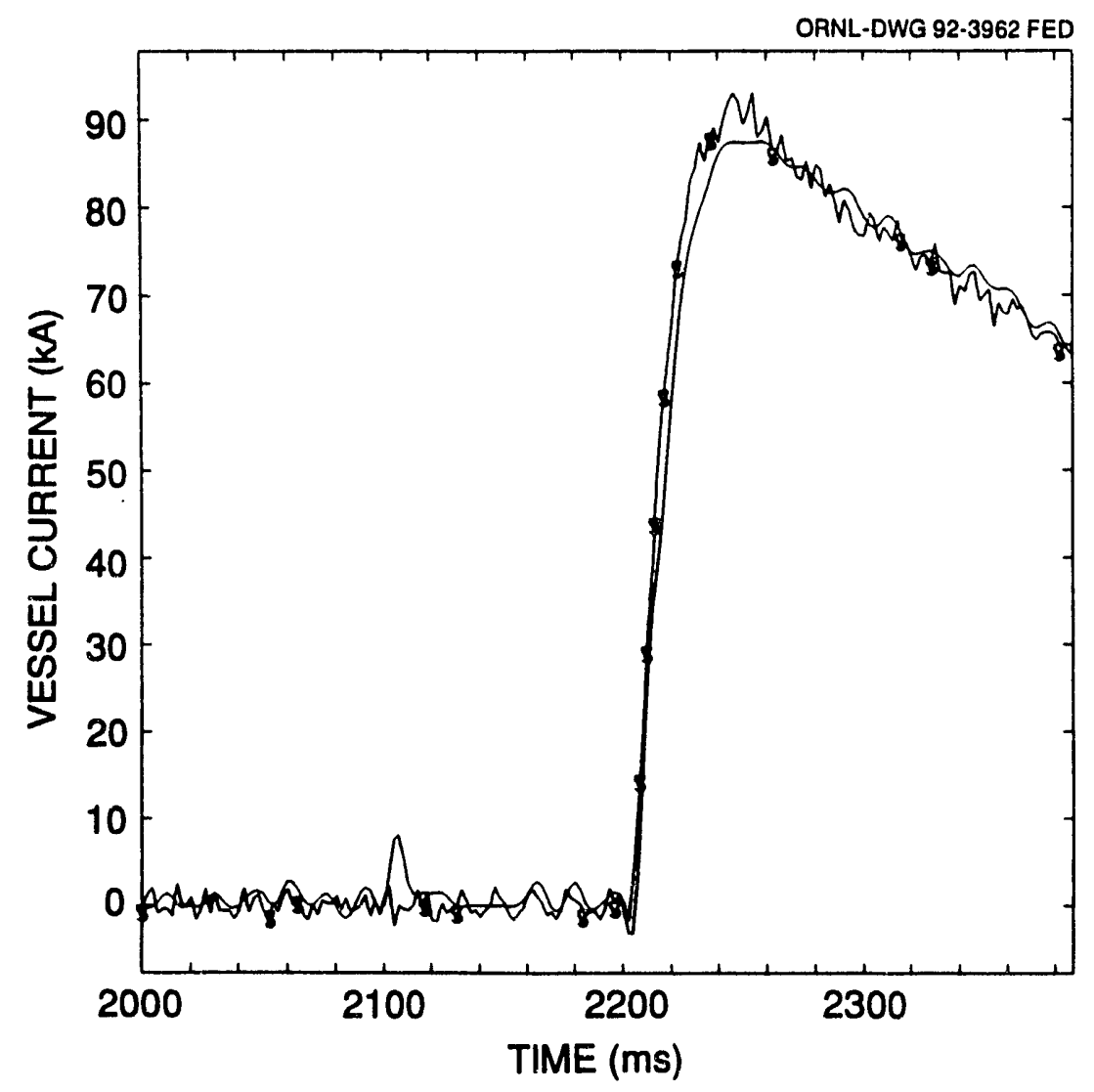

Fig. 5. Observed and TSC simulation toroidal vessel currents f $n$ r DIII-D shot 63458 from a test run in which one of the $E$ coils was ramped to a specified current with no plasma present. 

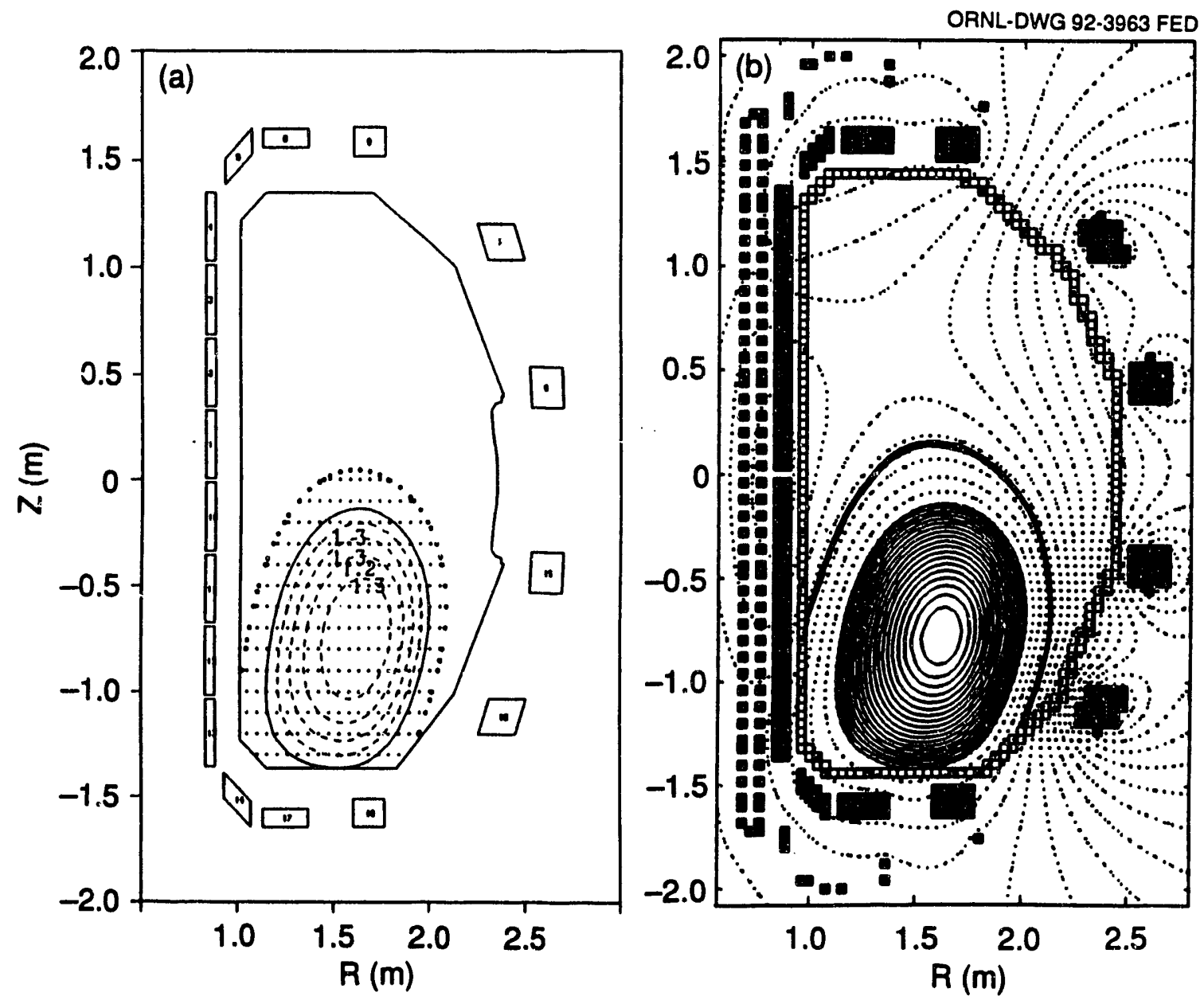

Fig. 6. Poloidal flux contours at $t=2680 \mathrm{~ms}$ for DIII-D shot 63458 from (a) an EFIT reconstructed equilibrium and (b) a TSC dynamic simulation. The halo boundary and TSC filamentary representations of the vacuum vessel, $F$ coils, and $E$ coils are also depicted. 


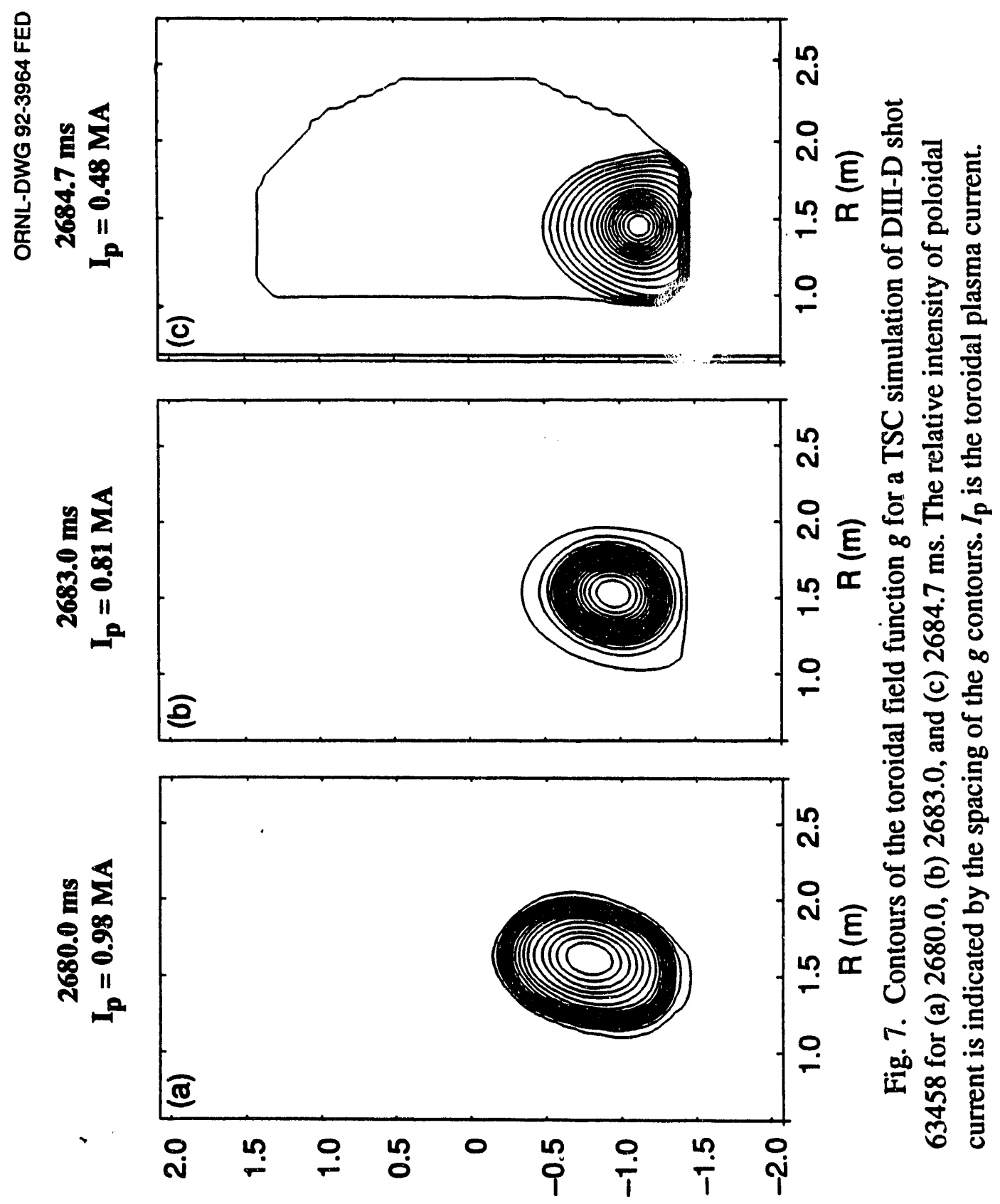

(w) Z 


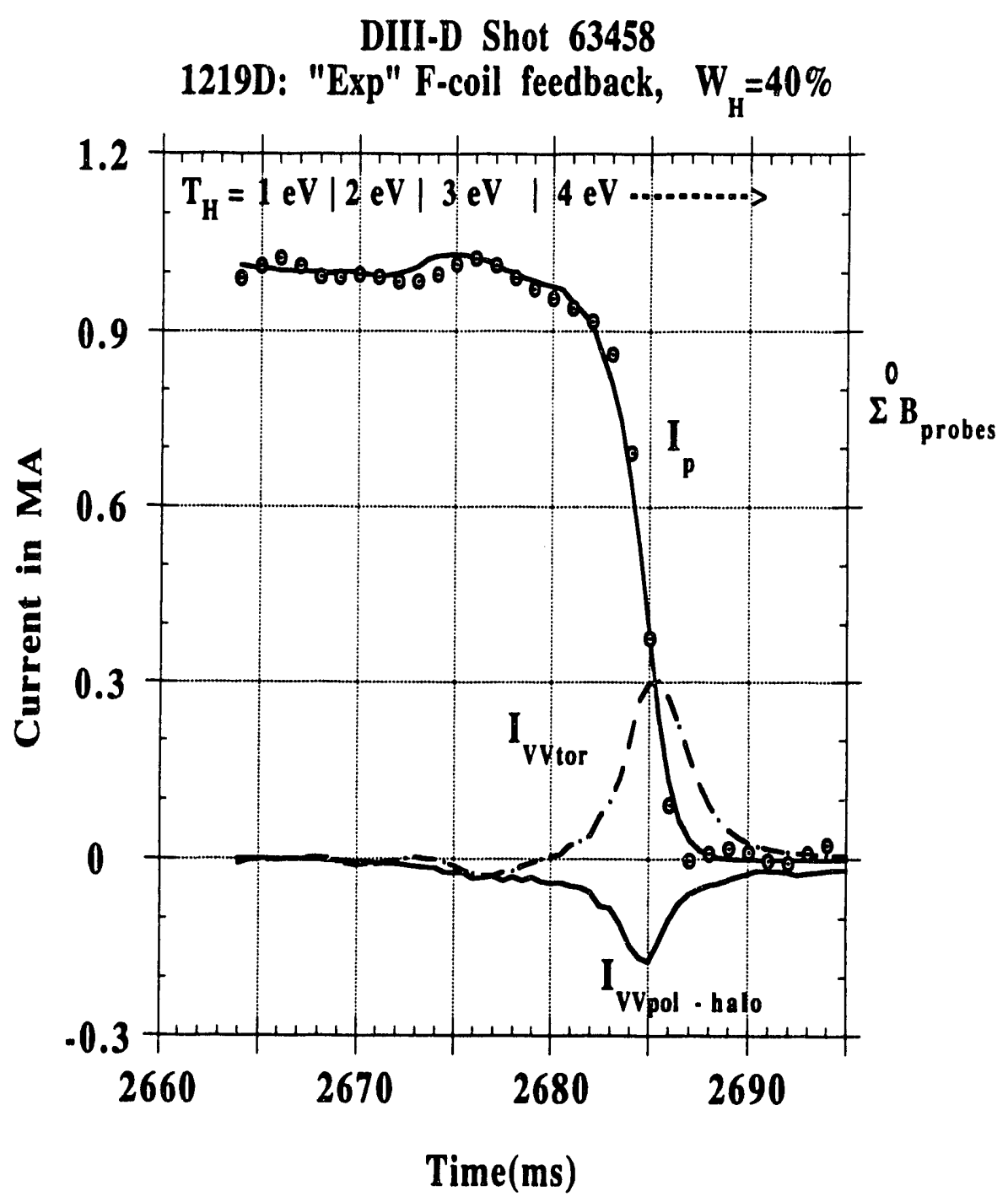

Fig. 8. Plasma current $I_{\mathrm{p}}$, toroidal vessel current $I_{\mathrm{VV}}$ tor, and poloidal halo vessel current $I \mathrm{VVpol-halo}$ vs time for DIII-D shot 63458 . The circles represent the experimental plasma current values. 
ORNL-DWG 92-3966 FED

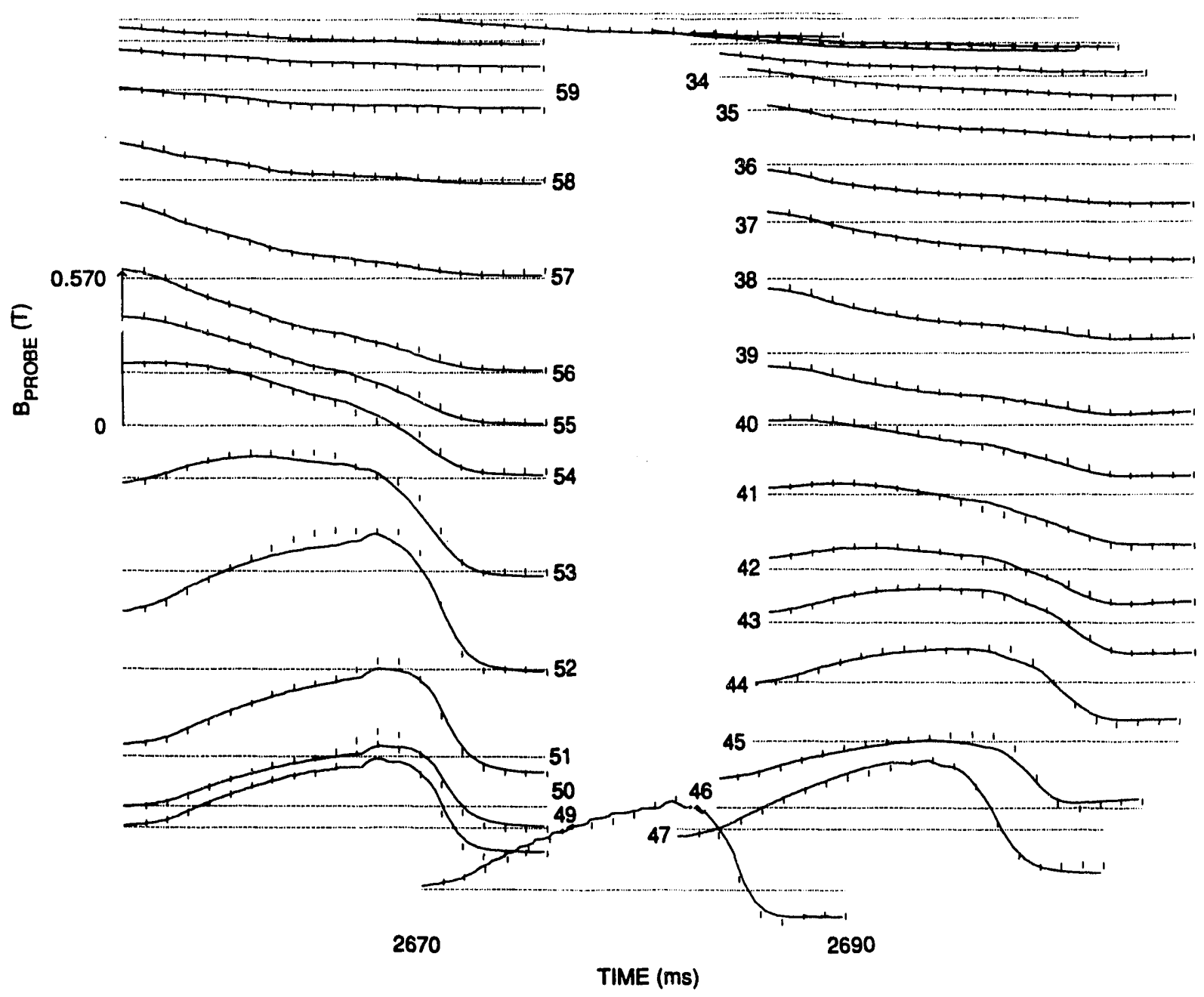

Fig. 9. Global view of the time evolution of magnetic probe data and calculated poloidal fields displayed on a cross section of the vessel. Each probe data set and the corresponding TSC curve are plotted at the approximate $(R, Z)$ location of that probe. 


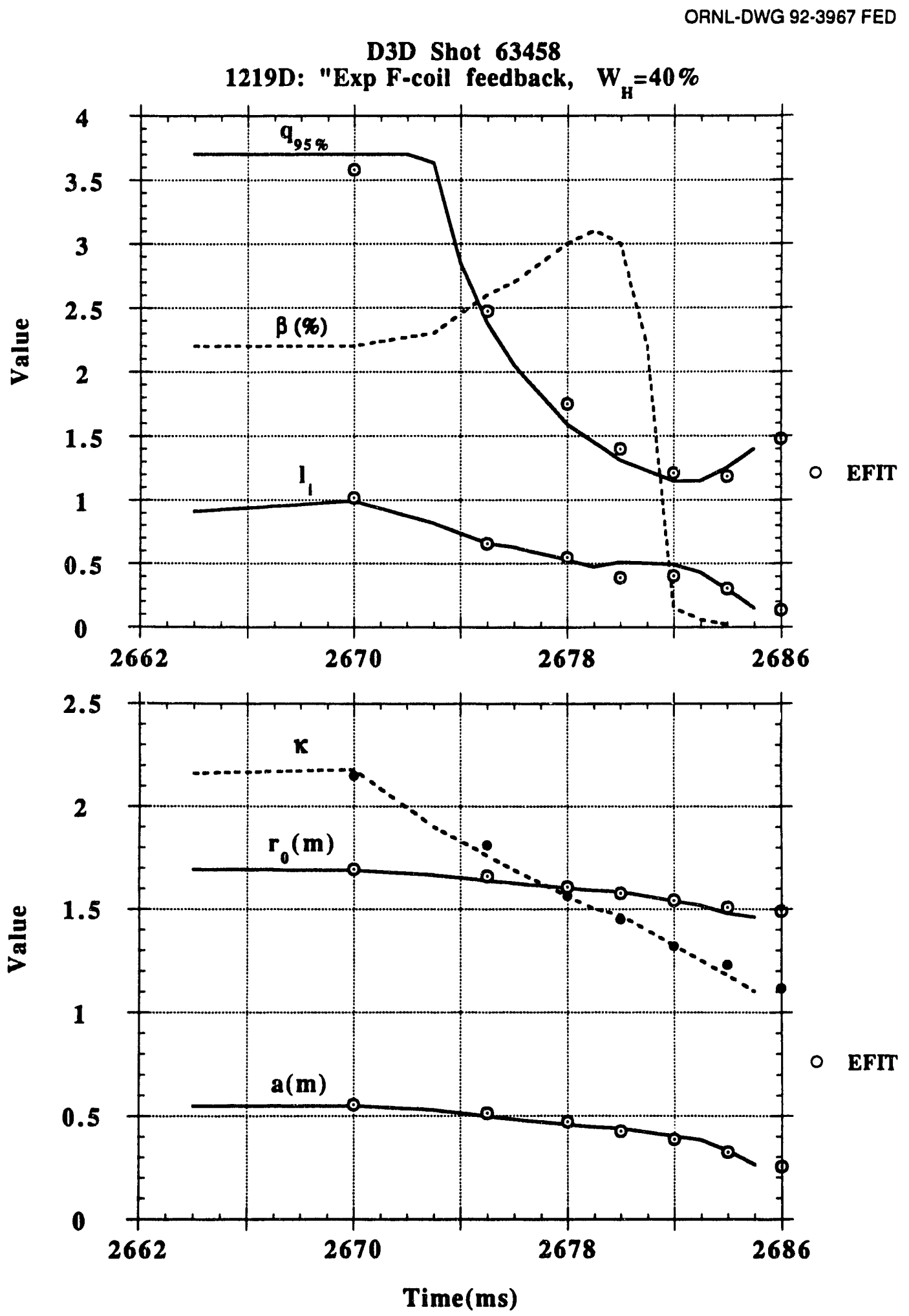

Fig. 10. TSC (curves) and EFIT (circles) plasma parameters for DIII-D shot 63458. 


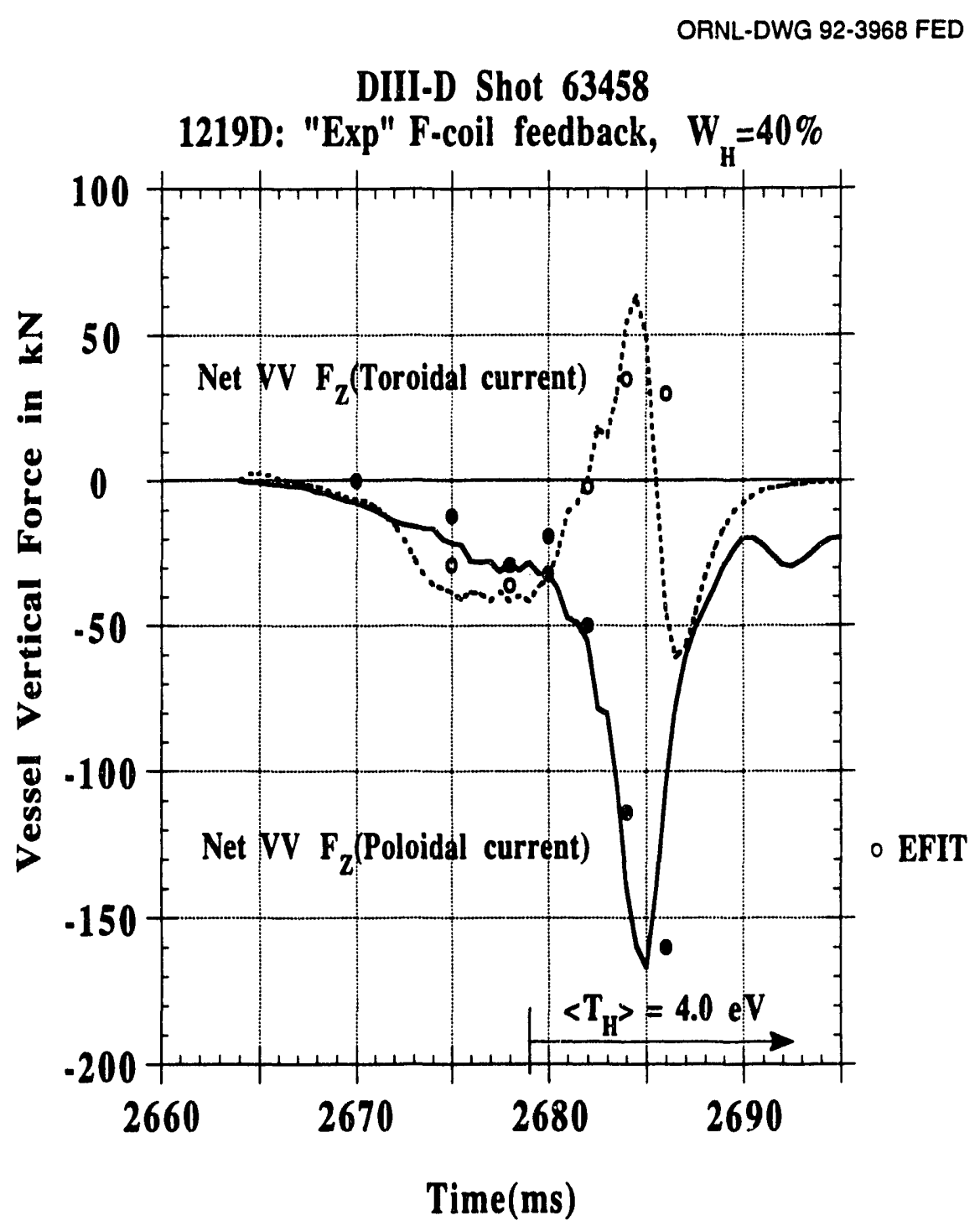

Fig. 11. Net vertical vacuum vessel forces as determined from the dynamic TSC simulation and from EFIT reconstructed equilibria (circles) for DIII-D shot 63458. 


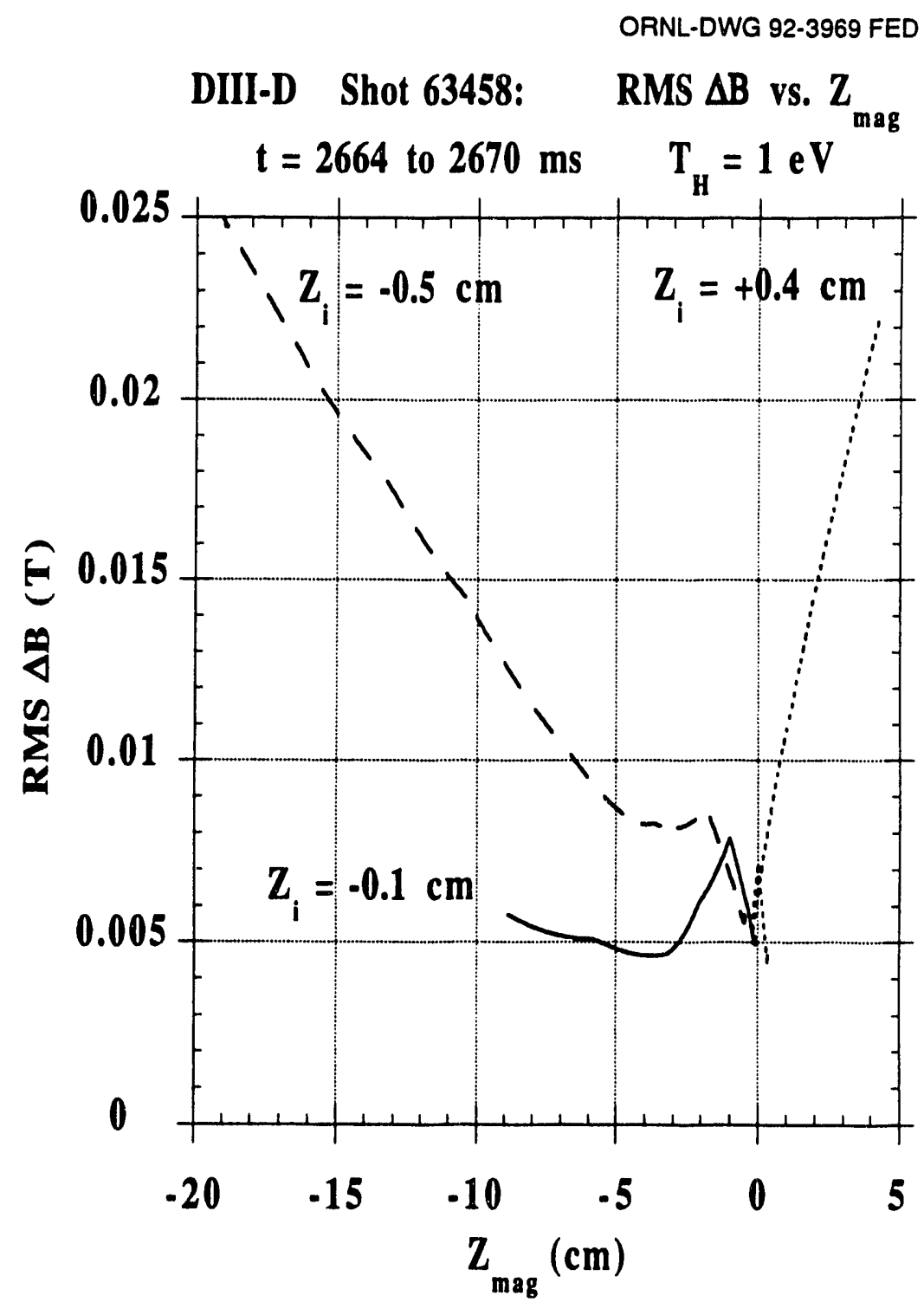

Fig. 12. The rms difference in TSC and experimental fields summed over $31 \mathrm{mag}-$ netic probe locations vs $Z_{\text {mag }}$ for initial displacements $Z_{i}=-0.5 \mathrm{~cm},-0.1 \mathrm{~cm}$, and $0.4 \mathrm{~cm}$ for DIII-D shot 63458. All three cases were run with $T_{\mathrm{H}}=1 \mathrm{eV}$. 


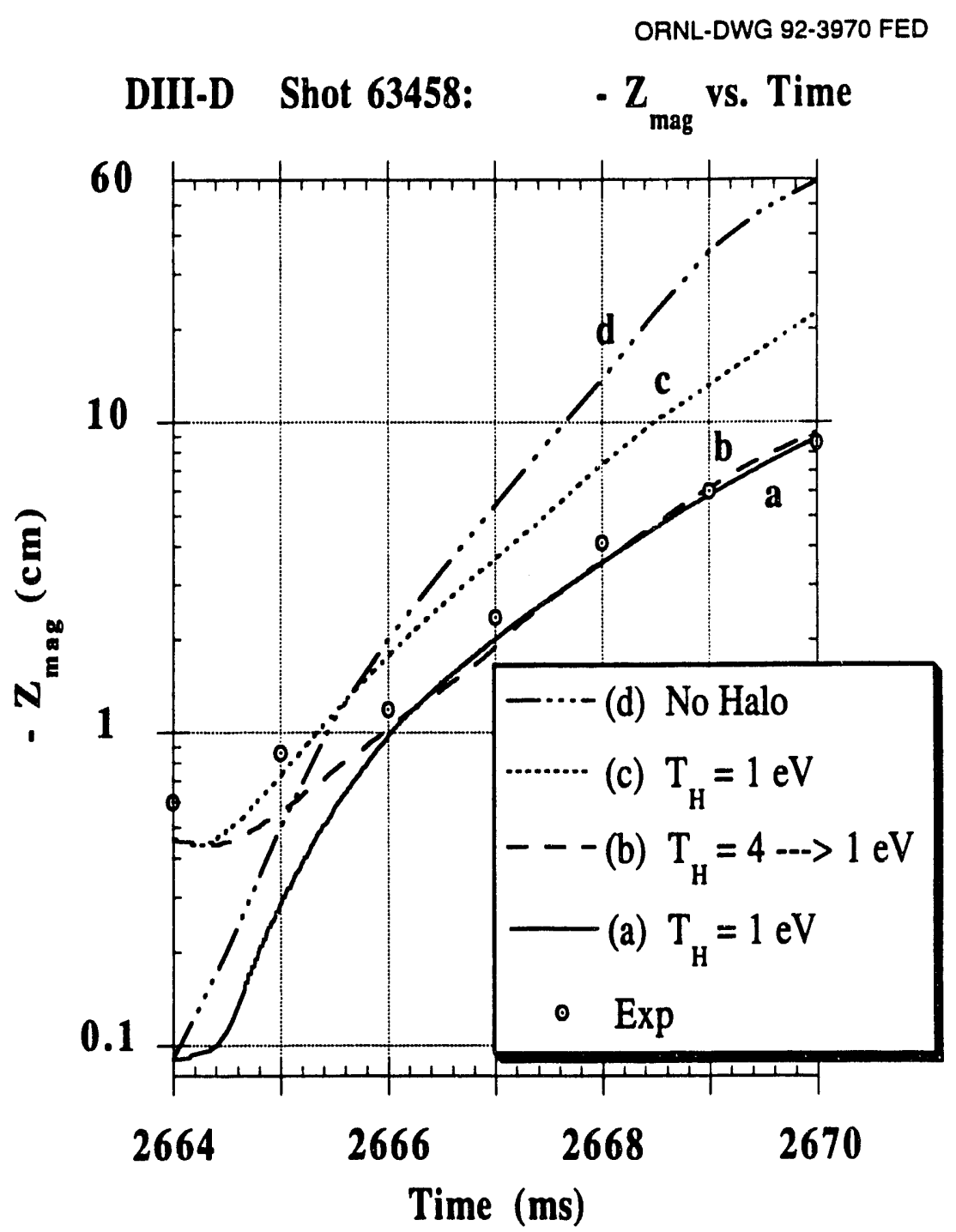

Fig. 13. Experimental and TSC vertical trajectories for DIII-D shot 63458. 
ORNL/TM-12281

Dist. Category UC-420

\section{INTERNAL DISTRIBUTION}

1. Director, ORNL Fusion Energy Division

2. C. C. Baker

3. M. J. Saltmarsh

4. L. A. Berry

5. B. A. Carreras

6. R. A. Dory

7. J. L. Dunlap

8. H. H. Haselton

9. M. S. Lubell

10. T. E. Shannon

11. R. P. Leinius

12. Laboratory Records, ORNL-RC

13-14. Laboratory Records Department

15-16. Central Research Library

17. Document Reference Section

18. Fusion Energy Division Library
19-20. Engineering Technology/Fusion Energy Division Publications Office

21. ORNL Patent Office

22-26. R. O. Sayer

27-31. Y-K. M. Peng

32. D. J. Strickler

33. D. W. Swain

34. B. E. Nelson

35. J. F. Monday

36. G. H. Neilson

37. R. H. Fowler

38. N. A. Uckan

39. D. C. Lousteau

40. J. C. Whitson

41. D. M. Hetrick

42. J. D. Galambos

\section{EXTERNAL DISTRIBUTION}

43. Office of the Assistant Manager for Energy Reseaich and Development, U.S. Department of Energy Field Office, Oak Ridge, P.O. Box 2000, Oak Ridge, TN 37831

44. N. A. Davies, Director, Office of Fusion Energy, Office of Energy Research, ER-50 Germantown, U.S. Department of Energy, Washington, DC 20545

45. M. Roberts, International Programs, Office of Fusion Energy, Office of Energy Research, ER-52 Germantown, U.S. Department of Energy, Washington, DC 20545

46. D. E. Baldwin, Lawrence Livermore National Laboratory, P.O. Box 5511, Livermore, CA 94550

47. R. W. Conn, Mechanical, Aerospace, and Nuclear Engineering Department, 6291 Boelter Hall, University of California, Los Angeles, CA 90024-1597

48. P. C. Liewer, MS 138-208, Jet Propulsion Laboratory, 4800 Oak Grove Drive, Pasadena, CA 91109

49. R. Parker, Plasma Fusion Center, Massachusetts Institute of Technology, 167 Albany St., NW16-288, Cambridge, MA 02139

50. K. I. Thomassen, L-637, Lawrence Livermore National Laboratory, P.O. Box 5511, Livermore, CA 94550

51. J. D. Callen, Department of Nuclear Engineering, University of Wisconsin, Madison, WI 53706-1687 
52. S. O. Dean, Fusion Power Associates, Inc., 2 Professional Drive, Suite 248, Gaithersburg, MD 20879

53. H. K. Forsen, Bechtel Group, Inc., Research Engineering, P.O. Box 3965, San Francisco, CA 94119

54. R. W. Gould, Department of Applied Physics, California Institute of Technology, Pasadena, CA 91125

55. R. A. Gross, Plasma Research Laboratory, Columbia University, New York, NY 10027

56. R. J. Hawryluk, Princeton Plasma Physics Laboratory, P.O. Box 451, Princeton, NJ 08543

57. D. M. Meade, Princeton Plasma Physics Laboratory, P.O. Box 451, Princeton, NJ 08543

58. W. M. Stacey, School of Nuclear Engineering and Health Physics, Georgia Institute of Technology, Atlanta, GA 30332

59. D. Steiner, Nuclear Engineering Department, NES Building, Tibbetts Avenue, Rensselaer Polytechnic Institute, Troy, NY 12181

60. R. Varma, Physical Research Laboratory, Navrangpura, Ahmedabad 380009, India

61. Bibliothek, Max-Planck Institut für Plasmaphysik, Boltzmannstrasse 2, D-8046 Garching, Federal Republic of Germany

62. Bibliothek, Institut für Plasmaphysik, KFA Jülich GmbH, Postfach 1913, D-5170 Jülich, Federal Republic of Germany

63. Bibliothek, KfK Karlsruhe GmbH, Postfach 3640, D-7500 Karlsruhe 1, Federal Republic of Germany

64. Bibliotheque, Centre de Recherches en Physique des Plasmas, Ecole Polytechnique Fédérale de Lausanne, 21 Avenue des Bains, CH-1007 Lausanne, Switzerland

65. R. Aymar, CEN/Cadarache, Departement de Recherches sur la Fusion Contrôlée, F-13108 Saint-Paul-lez-Durance Cedex, France

66. Bibliothèque, CEN/Cadarache, F-13108 Saint-Paul-lez-Durance Cedex, France

67. Library, JET Joint Undertaking, Abingdon, Oxfordshire OX14 3EA, England

68. Library, FOM-Instituut voor Plasmafysica, Rijnhuizen, Edisonbaan 14, $3439 \mathrm{MN}$ Nieuwegein, The Netherlands

69. Library, National Institute for Fusion Science, Chikusa-ku, Nagoya 464-01, Japan

70. Library, International Centre for Theoretical Physics, P.O. Box 586, I-34100 Trieste, Italy

71. Library, Centro Richerche Energia Frascati, C.P. 65, I-00044 Frascati (Roma), Italy

72. Library, Plasma Physics Laboratory, Kyoto University, Gokasho, Uji, Kyoto 611, Japan

73. Plasma Research Laboratory, Australian National University, P.O. Box 4, Canberra, A.C.T. 2601, Australia

74. Library, Japan Atomic Energy Research Institute, Naka Fusion Research Establishment, 801-1 Mukoyama, Naka-machi, Naka-gun, Ibaraki-ken, Japan

75. G. A. Eliseev, I. V. Kurchatov Institute of Atomic Energy, P.O. Box 3402, 123182 Moscow, Russia

76. V. A. Glukhikh, Scientific-Research Institute of Electro-Physical Apparatus, 188631 St. Petersburg, Russia 
77. I. Shpigel, Institute of General Physics, U.S.S.R. Academy of Sciences, Ulitsa Vavilova 38, Moscow, Russia

78. D. D. Ryutov, Institute of Nuclear Physics, Siberian Branch of the Academy of Sciences, Sovetskaya St. 5, 630090 Novosibirsk, Russia

79. O. Pavlichenko, Kharkov Physical-Technical Institute, Academical St. 1, 310108 Kharkov, Ukraine

80. Deputy Director, Southwestern Institute of Physics, P.O. Box 15, Leshan, Sichuan, China (PRC)

81. Director, The Institute of Plasma Physics, P.O. Box 1126, Hefei, Anhui, China (PRC)

Argonne National Laboratory, 9700 South Cass Avenue, Argonne, Il 60439

82. P. A. Finn, Bldg. 205

83. Y. Gohar, Bldg. 205

84. A. M. Hassanein, Bldg. 205

85. R. F. Mattas

General Atomics, P.O. Box 85608, San Diego, CA 92138-5608

86. D. Humphreys

87. T. H. Jensen

88. A. G. Kellman

89. D. Overskei

90. F. A. Puhn

91. K. R. Schultz

92. R. D. Stambaugh

93. J. C. Wesley

Lawrence Livermore National Laboratory, P.O. Box 5511, Livermore, CA 94550

94. J. N. Doggett

95. A. Glass

96. C. D. Henning

97. B. G. Logan, L-644

98. W. Nevins

99. L. J. Perkins, L-644

100. K. Thomassen

Los Alamos National Laboratory, P.O. Box 1663, Los Alamos, NM 87545

101. C. B. Bathke, MS-F641

102. R. K. Linford

103. R. L. Miller, MS-F641

104. R. Krakowski

Massachusetts Institute of Technology, 77 Massachusetts Avenue, Cambridge, MA 02139

105. D. R. Cohn

106. D. B. Montgomery, Plasma Fusion Center 
107. M. Porkolab, Plasma Fusion Center

108. D. J. Sigmar, Plasma Fusion Center

109. R. J. Thome, Francis Bitter National Magnet Laboratory

Ontario Hydrn, 700 University Avenue, Toronto, Ontario M5G 1X6, Canada

110. J. Blevins

111. A. Busigin, H11-F26

112. P. Gierszewski

113. K. M. Kalyanam, H11-F26

Princeton Plasma Physics Laboratory, P.O. Box 451, Princeton, NJ 08544

114. R. Goldston

115. K. McGuire

116. S. Kaye

117. S. Jardin

118. N. Sauthoff

119. S. Bernabei

120. F. W. Perkins

121. D. E. Post

122. P. H. Rutherford

123. G. V. Sheffield

124. K. M. Young

125. B. J. Merrill, Idaho National Engineering Laboratory, P.O. Box 1625, Idaho Falls, ID 83415

126. F. Engelmann, NET Team, Max-Planck-Institut für Plasmaphysik, D-8046 Garching, Federal Republic of Germany

127. N. Fugisawa, Japan Atomic Energy Research Institute, Naka Fusion Research Establishment, Naka-machi, Naka-gun, Ibaraki-ken 311-02, Japan

128. J. Holdren, University of California, Berkeley, CA 94720

129. T. Kammash, Department of Nuclear Engineering, University of Michigan, Cooley Building, North Campus, Ann Arbor, MI 48109

130. G. H. Miley, Nuclear Engineering Laboratory, University of Illinois, 103 South Goodwin Avenue, Urbana, Il 61801

131. R. R. Stasko, Canadian Fusion Fuels Technology Project, 2700 Lakeshore Road West, Mississauga, Ontario L5J 1K'3, Canada

132. H. Weitzner, Courant Institute of Mathematical Sciences, New York University, 251 Mercer Street, New York, NY 10012

133. Laboratorio Associado de Plasma, Instituto Nacional de Pesquisas Espaciais, Caixa Postal 515, 122201, São Jose dos Campos, SP, Brazil

134. J. C. Nascimento, Instituto de Fisica, University of São Paulo, C.P. 20516, 10498São Paulo, Brazil

135. S. A. Eckstrand, Office of Fusion Energy, Office of Energy Research, U.S. Department of Energy, Washington, DC 20545 
136. R. A. Blanken, Office of Fusion Energy, Office of Energy Research, U.S. Department of Energy, Washington, DC 20545

137. C. W. Bolton, Office of Fusion Energy, Office of Energy Research, U.S. Department of Energy, Washington, DC 20545

138. J. W. Willis, Office of Fusion Energy, Office of Energy Research, U.S. Department of Energy, Washington, DC 20545

139. D. H. Crandall, Office of Fusion Energy, Office of Energy Research, U.S. Department of Energy, Washington, DC 20545

140-i79. Given distribution as shown in OSTI-4500, Magnetic Fusion Energy (Category Distribution UC-420) 

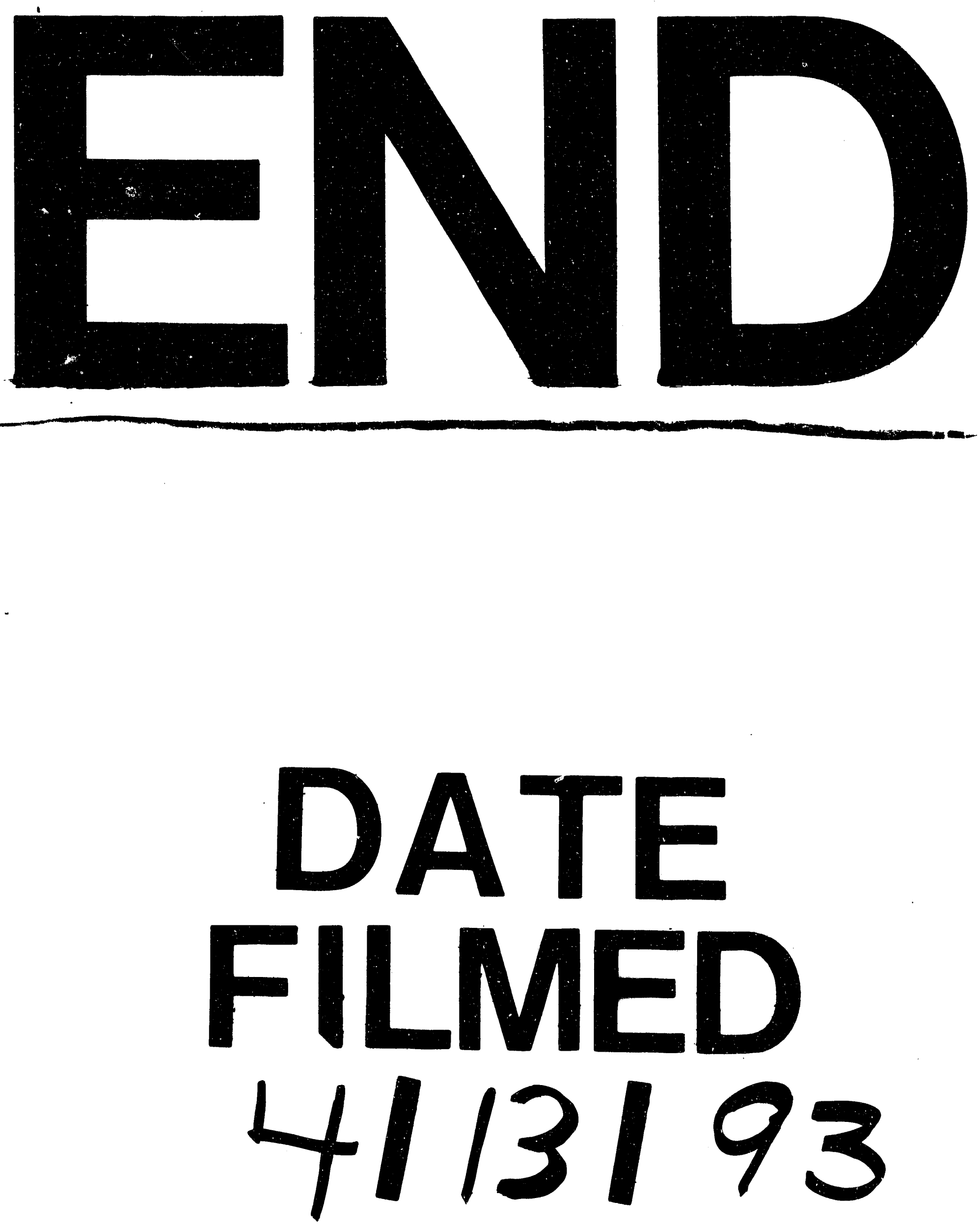